\title{
Research on Problems and Countermeasures of Financial Supply Chain Management in Chinese Retail Enterprises
}

\author{
Jielu Li ${ }^{1, a, \dagger}$, Wenni $\operatorname{Lin}^{2, b, \dagger}$, and Boshen Zhang ${ }^{3, c, \dagger}$ \\ ${ }^{1}$ School of Wenzhou Kean University, Wenzhou, Zhejiang 325000, China. \\ ${ }^{2}$ School of Jinshan College of Fujian Agriculture and Forestry University, Fuzhou, Fujian 350026, China. \\ ${ }^{3}$ School of Liaoning University, Shenyang, Liaoning 110000, China

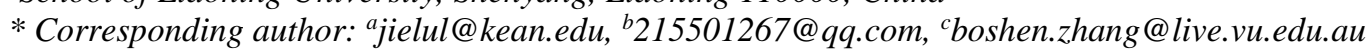 \\ these authors contributed equally.
}

\begin{abstract}
In the face of fierce competition in the market, Chinese retail enterprises can take the initiative to adapt to economic development, constantly transform for market demand, and form a mixed business model of "online + offline". Payment and settlement are becoming electronic, and the supply of goods depends on supply chains. However, due to the development trend of global economic integration, China's retail enterprises have realized that the traditional management mode can no longer adapt to today's fierce competition. More importantly, it is necessary to establish a management mode of the strategic partnership with other enterprises. Therefore, China's retail enterprises have a more urgent need to solve the supply chain management problem. Firstly, this paper analyses the existing common problems of Chinese retail enterprises' financial supply chain management through the literature research method. Secondly, it analyzes the typical problems of Chinese retail enterprises' supply chain management through the case study method and comparative analysis method. Finally, it proposes optimization strategies for the problems. The purpose of writing this article is to help more Chinese retail enterprises solve the financial supply chain management problems, improve the retail industry's economic benefits, and ensure the rapid growth of the modern service industry.
\end{abstract}

Keywords: Retail industry, supply chain, financial management, strategy, advice.

\section{INTRODUCTION}

For a long time, the retail industry has occupied a certain proportion in the Chinese market. According to the China Statistical Yearbook 2020, from 2017 to 2019, the wholesale and retail industry accounted for $9.7 \%, 9.6 \%$, and $9.6 \%$ of the GDP, respectively, and played an important role in People's Daily life. In China, the retail industry is roughly divided into traditional retail and new retail. At present, the traditional retail industry is faced with many problems, such as high rental of stores, diversified consumption scenarios, and high cost of online operation technology. To cope with these problems, many traditional retail industries choose to transform and form the mode of online and offline intercommunication, thus giving birth to a new retail industry. However, whether it is traditional retail or new retail, there are still many problems in managing a series of financial supply chains, such as industry form, supply channel, sales mode, and circulation mode.

Through the review of relevant literature, it is found that in the game relationship between retailer and supply chain in the retail supply chain studied by Hou Fangmiao, the retail industry must rely on supply chain management to improve the core competitiveness of enterprises [1]. According to the status quo of China's retail supply chain analyzed by Lin Xiaolan and Jiang Minghua, it can be seen that there are big gaps in the management information system, logistics system, and customer demand management of domestic small and medium-sized retail enterprises in China [2]. Compared with foreign retail enterprises, China's retail industry scale is relatively small, so the scale of financial supply chain management cannot be achieved. The labor cost and time cost in procurement, inventory, and logistics are high. Therefore, it is more necessary to study a 
supply chain management method suitable for the Chinese market.

We find that there are some problems in the financial supply chain of Chinese retail enterprises through literature review.

Jiao points out that the concept of supply chain management in China is backward, and most retail enterprises lack specialized supply chain management departments and corresponding supply chain management talents. Many retail and supplier partnerships have not been established because of price and channel competition. Many retail companies have inefficient logistics systems because of duplication of equipment and facilities between suppliers and retailers [3].

With the rapid development of information technology, the integration of offline and online models, and the rise of the concept of "new retail", the traditional retail model cannot support the rapid change and development of the market. So how to refine each part of the retail value chain is a problem worth studying. One of the reasons why the traditional retail industry cannot adapt to the rapidly changing market well is that the insufficient application of supporting technology leads to low efficiency.

Therefore, based on the insufficient application of supporting technology, we conduct research. We will illustrate the impact of technology gaps by analyzing the efficiency of each part of the value chain of a typical firm in the retail industry and its impact on the firm's profits and growth prospects.

We will use the literature research method, comparative analysis method, and case analysis method to carry out the study. Through the literature research method, we will analyze the relevant literature to identify the trends of technology development and its possible impact on the retail industry. Through the comparative analysis, we will compare the typical domestic and foreign retail enterprises to get the advantages and disadvantages of Chinese retail enterprises in technology. Through case analysis, we will study several enterprises that rely on information technology to stand out in the retail industry to illustrate the development prospects of enterprise application of information technology. Through this series of studies, we hope to put forward a series of measures to help enterprises improve their efficiency through information technology to help enterprises develop better.

\section{METHODOLOGY}

As originals of good quality and well contrasted, Figures and tables are to be in their final form, ready for reproduction, pasted in the appropriate place in the text. Try to ensure that the size of the text in your figures is approximately the same size as the main text (10 points). Try to ensure that lines are no thinner than 0.25 point. In this paper, to make a point of view more convincing, the literature research method, case analysis method, and comparative analysis method will all be used. Therefore, this paper starts from the actual situation, through the analysis of relevant literature and the latest data, and compares the application of the financial supply chain technology of Chinese and foreign enterprises. Finally, it proposes a solution to solve the problem of the Chinese enterprises' financial supply chain management.

1.Literature research methodology is to read through, analyze and sort literatures to identify the essential attribute of materials [4]. Therefore, in this paper, the use of the literature research method is to supplement the deficiencies of the related research and the quotation of the conclusions drawn by the predecessors on the financial supply chain management. Through the article's analysis, Hou Fangmiao, the role and significance of financial supply chain management in retail enterprises can be inferred. Through the analysis of the article written by $\mathrm{Xu} \mathrm{Xu}$, in the era of big data, the role and function of information technology in the financial supply chain management of new retail innovation enterprises can be concluded. It makes the argument of this article more real through the quotation and analysis of relevant documents.

2.The case study method is a learning technique in which the student has faced a particular problem, the case. The case study facilitates exploring a real issue within a defined context, using a variety of data sources [5]. Therefore, in this paper, the use of the case study method is to obtain corresponding conclusions by analyzing related cases. Through the analysis of WalMart's enterprise logistics and supply chain management cases, the importance of advanced information technology and logistics management in the development of retail enterprises can be concluded. Through the analysis of Coca-Cola's enterprise financial supply chain management case, it can be concluded that the backward financial chain management policy will lead to the loss of competitive advantage. It makes this paper's view on the impact of information technology on the supply chain more persuasive.

3. Comparative analysis research is a research methodology in the social sciences that aims to compare different countries or cultures. [6] Therefore, in this paper, the use of comparative analysis method is to compare the advantages and disadvantages of financial supply chain management of Chinese and foreign companies so as to solve problems for Chinese companies and summarize the most suitable and most efficient financial supply chain management plan for China's national conditions. Through comparative analysis of two large retail companies, Zara and Lining, 
the importance of logistics cost control and inventory handling in financial supply chain management is obvious. The pairwise comparison of Chinese and foreign enterprise data and management methods make

You are free to use colour illustrations for the online version of the proceedings. Still, any print version will be printed in black and white unless special arrangements have been made with the conference organiser. Please check with the conference organiser whether or not this is the case. If the print version is black and white only, you should check your figure captions carefully and remove any reference to colour in the illustration and text. In addition, some colour figures will degrade or suffer the loss of information when converted to black and white, and this should be taken into account when preparing them.

\section{RESULT}

\subsection{Present situation of supply chain management in the Chinese retail industry}

In general, although Chinese retail companies have been developing in recent years, Jiao Junhao pointed out that the process of supply chain management in China's retail industry is still slow. The entire production and circulation are still at a high cost, Lowefficiency operating state [7]. At present, the supply chain management of China's retail industry generally has the following problems:

\subsubsection{Low utilization rate of information system technology}

The information system technology is a rigid demand for China's large-scale retail companies, but it is a basic guarantee for China's small and medium-sized retail companies. And because Rao Kunluo put forward why the traditional concept of China's retail industry is backward, small and medium-sized retail companies. Compared with large-scale enterprises, enterprises pay more attention to short-term gains [8]. The information system technology is currently developing according to needs. Therefore, the utilization rate of information system technology for Chinese retail enterprises is low. However, in the supply chain management of the retail industry, information systems play a vital role. For companies, the strength of the information system is directly related to the supply chain's competitiveness. At present, most businesses in the traditional retail industry are still manually operated. Not only is the management cost high, but the information in the procurement process is not smooth. Suppliers cannot know the inventory situation of retail stores in time. Even if some retail stores introduce information technology, they are limited to internal Inventory management. Customer settlement management has not risen to the management level of supply chain and customer relations.

\subsubsection{It is not easy to build a new supply chain system}

For China's retail industry, establishing a new model of the supply chain requires a lot of financial support. Still, Chinese companies have a single financing channel, and high financing costs will make it difficult to raise a large number of funds for the construction of a new supply chain system. However, China's small and medium-sized retail companies do not have enough funds to support the construction of a new supply chain system, so only relatively powerful large companies can undertake such risks to make changes. Li Tong once pointed out that the essence of competition among enterprises is supply chain disputes [9]. Inefficient supply chain management models will bring about problems such as inventory accumulation, increased costs, low enterprise operation capabilities, and low risk response capabilities.

\subsubsection{There are conflicts between retailers and suppliers}

There are conflicting goals among the members of the supply chain. Among them, retailers and suppliers are often in a state of opposition. They will play a game on price and use channel partners as sources of profits. This leads to the inability to establish mutual relations between the two parties. Trust in good relationships. Suppose the various companies in the supply chain cannot establish a high degree of mutual trust mechanism. In that case, it will lead to the breakdown of the relationship between the two parties, which will increase the transaction costs of both parties and increase the coordination workload between the partners.

\subsection{Problems analysis of typical enterprise financial supply chain management}

With the gradual deepening of the economic system reform, the management model of China's retail enterprises is also constantly innovating, and they already have certain supply chain management capabilities and management experience. However, compared with the management model of foreign retail giants, there are still many problems. Below we will analyze the crisis of Li Ning Company in 2010 and its comparison with Zara Company to summarize the supply chain management problems of $\mathrm{Li}$ Ning Company. In 2021, the inventory management level of Li Ning Company has been solved, but there are still problems such as low market analysis ability and low efficiency of information system transmission. 


\subsubsection{Poor inventory management}

The amount of inventory impacts the cost and profit of an enterprise, and the smaller the inventory, the better the business management. Li Ning Company experienced a severe inventory crisis in 2009. Zhang Yumin pointed out that in 2011, Li Ning's inventory was 1.133 billion yuan, an increase of $40.62 \%$ from 2010's 805 million yuan. [10] The inventory turnover days are much higher than that of competitors, which means that Li Ning's inventory backlog is extremely serious. However, Zara, which is also a clothing retail company, is known for its extremely high inventory turnover rate. Zara's inventory turnover rate can reach 12 rounds, and the inventory time is only 30 days, which is 3 to 4 times that of other brands. Zara's inventory level is very low, accounting for only $10 \%$ of sales.

Table 1. 2009 2011 Li Ning inventory level chart

\begin{tabular}{|c|c|c|c|}
\hline & 2009 & 2010 & 2011 \\
\hline $\begin{array}{c}\text { Total } \\
\text { products }\end{array}$ & 704,054 & 920,680 & $1,320,474$ \\
\hline $\begin{array}{c}\text { Minus : } \\
\text { Inventory } \\
\text { impairment } \\
\text { provision }\end{array}$ & 72,526 & 115,082 & 187,509 \\
\hline Inventory & 631,528 & 805,598 & $1,132,965$ \\
\hline
\end{tabular}

\subsubsection{Low market analysis ability}

In 2010, Li Ning Company carried out a rebranding plan through market analysis. Li Ning changed the standard of its brand, and at the same time, positioned the consumer group as the "post-90s" and the brand as "fashion, cool, and global vision." However, positioning the "post-90s" cannot help Li Ning Company expand the consumer group and separate the original customer group. The failure of brand positioning caused by market analysis errors caused Li Ning's revenue and profits to decline in the next two years. However, Zara relied on its excellent market analysis capabilities to rapidly expand its market share. Zara's brand positioning is fast, cheap, and fashionable, and young consumers love its products.

\subsubsection{The information transmission system is inefficient}

Li Ning adopts a wholesale operation model, where manufacturers-distributors-retailers-customers cannot communicate and share information across levels. The inefficiency of the information transmission system makes it difficult to implement short-term production plans. Zhang Yumin pointed out that Li Ning's retailers were optimistic about demand and added orders due to the out-of-control information transmission. Manufacturers relied on orders issued by downstream companies to produce blindly instead of arranging production by using the actual needs of end consumers [11]. On the other hand, Zara adopts a vertical integration strategy, which vertically integrates all aspects of raw material purchase, clothing design, production, distribution, and sales. Information sharing is implemented in all links, and the efficiency of information transmission is very high, helping it to ensure sales and inventory levels.

\section{DISCUSSION}

Online references will be linked to their original source, only if possible. To enable this linking extra care should be taken when preparing reference lists. Based on the analysis above, it can be concluded that the financial supply chain management of Chinese retail enterprises mainly has serious inventory control issues, the inefficiency of the logistics system, insufficient support technology, and relationship issues with suppliers. There are a couple of ways to solve these problems.

\subsection{Using $A B C$ cost control method and inventory management information system to solve inventory control problems.}

There are many possible reasons why retail companies have inventory backlogs. For instance, the company does not carry out quantitative management of the production department's production work. The company is confused about the warehouse management. It does not receive the goods according to the order quantity, or the sales department of the company does not accurately predict its sales.

To solve the problem of inventory backlog, the ABC method can be adapted to classify the inventory items according to the price of the inventory items. Activitybased costing $(\mathrm{ABC})$ is a costing method that assigns overhead and indirect costs to related products and services [12].

Table2. An example for ABC Control Method

\begin{tabular}{lll}
\hline Category & $\begin{array}{l}\text { Account for } \\
\text { inventory funds }\end{array}$ & $\begin{array}{l}\text { Account for } \\
\text { inventory varieties }\end{array}$ \\
\hline A & $60 \%$ & $20 \%$ \\
B & $25 \%$ & $30 \%$ \\
C & $15 \%$ & $50 \%$ \\
\hline
\end{tabular}

For key resources, A, which accounts for many inventory funds, strict control, and regular inspections are required. resource $\mathrm{C}$ that has a small impact on the total amount of funds, extensive management can be performed. Daily management can be taken for this 
resource $\mathrm{B}$. The second solution is to use the inventory management information system to analyze various inventory management indicators to supervise inventory management. The third way is to reduce inventory costs by increasing the total amount of available inventory. For example, choose air freight to ship high-value, small-sized products to shorten inventory in transit time and optimize inventory control.

\subsection{Building modern logistics informatization to improve inefficient logistics systems and insufficient support technology.}

With the development of information technology, the role of information technology in the financial supply chain is gradually increasing. For example, the use of information technology can also solve the inefficiency of the financial supply chain. Besides, traditional logistics systems are inefficient and difficult to meet the requirements of enterprises. Therefore, building modern logistics informatization is a reasonable way of using support technology to solve the inefficiency of logistics systems. Logistics informatization refers to the use of modern information technology to analyze and control logistics information to manage and control logistics, business flow, and capital flow to improve the degree of automation of logistics operations and the level of physical decisionmaking. Finally, realize the rational allocation of logistics resources, reduce logistics costs, and improve logistics service level [13]. The construction of modern logistics helps companies understand market demand more quickly. At the same time, place orders and deliver goods with distributors and customers through the Internet more directly, and ultimately improve the efficiency of the logistics system.

\subsection{Establishing strategic alliances to properly handle relationships with suppliers.}

The traditional financial supply chain members believe that they are in a competitive relationship with each other. To obtain the highest benefits, it has led to an increase in prices, the non-disclosure of information, and facilities' waste. Therefore, to solve these problems, Chinese retail companies should use their advantage of being close to the most terminal to choose suitable suppliers and establish strategic alliances with them. Through close cooperation with each other, we can better attract consumers to maximize benefits.

\section{CONCLUSION}

\subsection{Summary}

The financial supply chain is a significant part of the successful development of retail enterprises. Through the research of relevant literature and the analysis of
Internet business information, it can be concluded that Chinese retail enterprises' financial supply chain management has problems of improper cost control, insufficient use of information technology, and improper handling of relations with suppliers. Using the new management cost system, using Internet knowledge and strategic alliance cooperation can effectively solve these problems. Ultimately guarantees the highefficiency work of the retail enterprise's financial supply chain and improves the enterprise's internal management level.

\subsection{Limitations}

There are two major limitations in this study that could be addressed in future research. Firstly, the analysis of this paper is based on secondary data and lacks the support of primary data. Second-hand data are obtained indirectly, which may lead to a lack of accuracy and scientific conclusions. Secondly, the study may be biased by cultural or personal factors. Researchers may have biases due to their cultural background and personal opinions on specific phenomena, which may affect the rationality of the research. Based on the above two limitations, we can make some improvements in future research. First, we can obtain enough first-hand data through field investigations and interviews to ensure the accuracy and scientific nature of the data. Second, we need to examine the process of data collection and determine if it is appropriate to improve it.

\section{REFERENCES}

[1]Fangmiao Hou, Research on Retail Supply Chain Management. (2003)

[2]Xiaolan Lin and Mingxu Jiang, Discussion on China's retail supply chain management. (2012)

[3]JunHao Jiao, Problems and Countermeasures of Supply Chain Management in China's Retail Industry. (2012)

[4]GuiJuan Lin, International Education Studies, Higher Education Research Methodology-Literature Method, Vol. 2, No. 4 (2009)

[5]A. Bennett, International Encyclopedia of the Social \& Behavioral Sciences, Case Study: Methods and Analysis ( 2001)

[6]Esser Frank, Vliegenthart Rens, Comparative Research Methods

[7]JunHao Jiao, Problems and Countermeasures of Supply Chain Management in China's Retail Industry. (2012) 
[8]Kunluo Rao, Current Situation and Development Countermeasures of Retail Supply Chain Management (2007)

[9]Jiong $\mathrm{Li}$, Chain retail circulation model based on supply chain management. (2020)

[10]YuMin Zhang, Comparative Analysis between Li Ning Company and Inditex Group -- Based on the Perspective of Supply Chain Management. (2013)

[11]YuMin Zhang, Comparative Analysis between Li Ning Company and Inditex Group -- Based on the Perspective of Supply Chain Management. (2013)

[12]Aziroff, Pratice Makes Perfect, What is Activitybased Costing (ABC)

[13]Zhou Zhu, The Status Quo and Optimization Ways of China's Enterprise Logistics Information Construction (2008) 